This item was submitted to Loughborough's Research Repository by the author.

Items in Figshare are protected by copyright, with all rights reserved, unless otherwise indicated.

\title{
Attending to the mobile text summons: Managing multiple communicative activities across physically copresent and technologically mediated interpersonal interactions
}

\section{PLEASE CITE THE PUBLISHED VERSION}

https://doi.org/10.1177/0093650218803537

\section{PUBLISHER}

(c) the Authors. Published by SAGE Publications

\section{VERSION}

AM (Accepted Manuscript)

\section{PUBLISHER STATEMENT}

This work is made available according to the conditions of the Creative Commons Attribution-NonCommercialNoDerivatives 4.0 International (CC BY-NC-ND 4.0) licence. Full details of this licence are available at: https://creativecommons.org/licenses/by-nc-nd/4.0/

\section{LICENCE}

CC BY-NC-ND 4.0

\section{REPOSITORY RECORD}

DiDomenico, Stephen M., Joshua Raclaw, and Jessica Robles. 2018. "Attending to the Mobile Text Summons: Managing Multiple Communicative Activities Across Physically Copresent and Technologically Mediated Interpersonal Interactions". Loughborough University. https://hdl.handle.net/2134/36981. 
Attending to the mobile text summons: Managing multiple communicative activities across copresent and technologically-mediated interpersonal interactions

\author{
Stephen M. DiDomenico, SUNY New Paltz \\ didomens@newpaltz.edu \\ Joshua Raclaw, West Chester University \\ jraclaw@wcupa.edu \\ Jessica S. Robles, Loughborough University \\ j.j.robles@lboro.ac.uk
}

\title{
Suggested Citation:
}

DiDomenico, S., Raclaw, J., \& Robles, J. (2018). Attending to the mobile text summons: Managing multiple communicative activities across co-present and technologically-mediated interpersonal interactions. Communication Research. doi: 0093650218803537.

\section{Author Biographies}

Stephen M. DiDomenico (PhD, Rutgers University) is an assistant professor in the Department of Communication at the State University of New York at New Paltz. Their research investi-gates the dynamics of interpersonal encounters, especially the negotiation of identities and rela- tionships in everyday and professional settings.

Joshua Raclaw (PhD, University of Colorado-Boulder) is an assistant professor in the Department of English at West Chester University. Their research draws on conversation analy- sis and interactional linguistics to examine the coordination of language, gesture, gaze, and touch in ordinary conversation 
and professional meetings.

Jessica S. Robles (PhD, University of Colorado-Boulder) is a lecturer in the Department of Social Sciences at Loughborough University. Their research examines the role of moral issues and differences in ordinary conversation.

\section{Acknowledgments}

The authors would like to thank the coeditors and two anonymous reviewers for their exceptionally supportive and generous feedback on earlier drafts of this article. We are also grateful for helpful feedback from attendees at earlier presentations of this work at the 2017 meeting of the International Pragmatics Association in Belfast, the 2015 meeting of the International Communication Association in San Juan, and the 2013 National Communication Association in Washington D.C., and the comments and encouragement from the members of the Rutgers University Conversation Analysis Lab. The first author would also like to express deep thanks to Jeffrey Boase for his invaluable support and mentorship in the earliest stages of developing some of the ideas discussed here. 


\begin{abstract}
:
This article presents a qualitative investigation of communication practices interactants use to manage mobile phone activity while they are engaged in a co-present conversation. Drawing from conversation analysis and a collection of naturalistic video recordings, our study of mobile phone use in situ focuses on how participants orient to the mobile text summons, the audible chimes or vibrations that indicate the receipt of a text message (or SMS). In these moments interactants must simultaneously manage attending to their phone and the co-present conversation. Our analysis shows how people may use nonverbal and verbal techniques to attend to their mobile phone based on their identity respective to the co-present activity. The study contributes to scholarly understandings of technology use, multi-tasking, and the management of attention in interpersonal communication.
\end{abstract}

Keywords: Mobile Phones, Affordances, Attention, Multi-tasking, Interpersonal Communication, Nonverbal Communication 
In recent years, social research and popular media has focused on whether the proliferation of communication technologies in our lives supports or impedes human rela- tionships, community, and sociality writ large (e.g., Beck, 2016; Hampton, 2016; Oppenheimer, 2014; Turkle, 2012, 2015; cf. Rice \& Katz, 2003). Some of these perspectives have been critiqued (e.g., boyd, 2014; Curran, Fenton, \& Freedman, 2016; Fisher, 2015) as potentially reflecting a technological deterministic view that overestimates the effects of technologies on aspects of our social world. Yet what this and other perspectives in this debate often fail to offer is a more precise look at how such issues are dealt with when participants orient to the use of different communication technologies in the course of ordinary turn-by-turn talk. The current article offers this perspective, using the lens of affordances theory and conversation analytic methods, to examine how people navigate mobile phone use amid a physically copresent (face- to-face) conversation.

The mobile phone (or "cell phone" as it is also commonly referred to in North America) is a modern technology that has become embedded in our everyday lives - including our everyday conversations, mediated and otherwise - allowing us to be in almost constant contact with colleagues, acquaintances, and those with whom we are closest (Katz \& Aakhus, 2002; Licoppe, 2004; Ling, 2012; Ling \& Campbell, 2009). Evidence of the proliferation of mobile phone use in everyday life can be found in recent studies documenting how people engage with mobile phones in public spaces (Hampton, Goulet, \& Albanesius, 2015; Humphreys, 2005) and, as a further result of their ubiquity, how mobile phone use is interwoven with copresent communication as a routine method for managing interpersonal relationships (Caughlin \& Sharabi, 2013) while also serving as a source of collective attention during inprogress copresent conversational actions (Aaltonen, Arminen, \& Raudaskoski, 2014; DiDomenico \& Boase, 2013; Haddington \& Rauniomaa, 2011; Isaacs, Szymanski, Yamauchi, Glasnapp, \& Iwamoto, 2012; Miller-Ott \& Kelly, 2015; Weilenmann \& Larsson, 2002). Yet there has been considerably less 
work focused on the verbal and nonverbal communication practices that people use to manage and display attention toward the audible sounds or vibrations that indicate the receipt of mobile text messages, what we describe as the mobile text summons (MTS). Furthermore, as our analysis shows, it is how participants go about coordinating these moments-when both copresent and noncolocated text-based engagements overlap - that demonstrates their agency in the real-time negotiation of the technology/society equation, and speaks to the ways that technology can be used as a resource to facilitate the interactional projects and challenges that are a part of technology use in everyday life. Through fine-grained qualitative analysis of such moments, we document several types of interactional opportunities and constraints—often presumed to be threatening to interpersonal and relational engagement - that come with communicating via technology amid other interpersonal environments.

Following a review of prior literature related to affordances theory, multiactivity, and the telephone summons, we detail our methods of data collection and analysis. The subsequent analysis is structured around three main sequential environments within interpersonal conversation in which an MTS may be managed. First, when a participant receives an MTS while they are also engaged in managing their recipiency to another speaker in the copresent encounter; second, when the MTS recipient also holds the status of current speaker in the copresent encounter; and third, when the MTS recipient uses their mobile phone as a resource for collapsing the boundaries between the copresent encounter and mobile phone mediated interaction. Finally, we discuss contributions and implications of this research.

\section{Literature Review}

Mobile phones represent a unique opportunity for examining everyday technology use in light of their increasingly omnipresent role in both public and private spaces (Haddington \& Rauniomaa, 2011; 
Hampton et al., 2015; Humphreys, 2005; Pettegrew \& Day, 2015). The notion of technological affordances is central to ourunderstanding of how mobile phone use is dealt with in situ. Gibson (1977) originally proposed the notion of affordances to emphasize humans' unique capacity to identify the opportunities for action that are made possible by an object (cf. Hutchby, 2001; Norman, 1999). More recently, this concept has been adopted across a range of fields to describe how technologies offer both opportunities and constraints for the accomplishment of human action (e.g., DiDomenico \& Boase, 2013; Gershon, 2017; Hoey, 2015; Nagy \& Neff, 2015; Treem \& Leonardi, 2013). An affordance perspective toward communication technologies strikes a balance between technological deterministic views of technology that de-emphasize human agency and social constructionist views that downplay the material characteristics of technology (Aakhus \& DiDomenico, 2016; Hutchby, 2001). As such, we understand the mobile phone as affording new opportunities for accomplishing human interaction while also considering the autonomous behavior of participants situated in the interaction (cf. DiDomenico \& Boase, 2013; Raclaw, Robles, \& DiDomenico, 2016).

In contrast to other objects that might be manipulated during a copresent conversation, the mobile phone affords richer opportunities for communicating in ways that can transcend temporal constraints (i.e., sending and receiving messages asynchronously) as well as spatial constraints (i.e., communicating with distant others). Responding to an MTS, then, may create two concurrent communicative events across two different modalities: First, synchronously in the immediate copresent environment and, second, asynchronously in the mobile phone mediated environment. Thus, participants' use of mobile phones (and their affordances) has the potential to create complex, multimodal communicative scenarios and, as a result, their use shapes social practices for dealing with the practical challenges that may emerge from managing multiple streams of activity.

The ubiquity of mobile phone use in social life may also pose basic interactional problems in 
terms of how participants ought to go about navigating multiple concur- rent involvements-some technologically mediated — during interpersonal encounters. Goffman (1963) offered several observations about the nature of how humans divide their involvement in everyday life: "Main involvements" command the bulk of an individual's attention, while "side involvements" are activities that could be accomplished "without threatening or confusing simultaneous maintenance of main involvement" (p. 43). An influx of research across a variety of disciplines (e.g., cognitive psychology, human-computer interaction) has further molded Goffman's observations into more formal investigations of "multi-tasking," chiefly characterized by simultaneous involvement across multiple tasks (Kurtzberg \& Gibbs, 2017; Ralph, Thompson, Cheyne, \& Smilek, 2014; Reinsch, Turner, \& Tinsley, 2008; Stephens, Cho, \& Ballard, 2012; Wang, Irwin, Cooper, \& Srivastava, 2015).

More recently, an interaction-centered approach to multitasking has emerged, which stresses how people communicatively display and recognize attention within moments of multiple concurrent involvements, or "multi-activity" (Haddington, Keisanen, Mondada, \& Nevile, 2014). This work been developed with influence from the long- standing, interdisciplinary tradition of investigating the nonverbal and embodied aspects of communication (e.g., Burgoon, Buller, Hale, Turck, 1984; Ekman \& Friesen, 1969; Goodwin, 2000; Streeck, 1993). For scholars interested in communication, this interactional perspective is useful for highlighting the specific verbal and embodied communication practices that participants rely upon to perform actions and recognize actions of others in copresent encounters (e.g., Raymond \& Lerner, 2014).

Engaging with one's mobile phone amid other unfolding copresent activities can also have consequences for the types of discourse-level identities that participants enact and continually (re)negotiate in talk. Discourse identities (Zimmerman, 1998) represent further emergent resources that can orient participants to their respective role within the broader type of activity currently unfolding. ${ }^{1}$ 
Such identities may be specific to the type of communicative activity being produced (e.g., caller/answerer, storyteller/story recipient, and questioner/answerer, etc.). For instance, speaker/ hearer are a set of discourse identities often contingent upon who has the speaking floor and who is expected to display recipiency to him or her. For the purpose of the current article, identifying such roles rooted in discourse actions will help to under- score how interactants navigate a discourse identity in asynchronous, text-based interaction (via their mobile phone) concurrently with a discourse identity in the copresent conversation.

Schegloff"s classic notion of the telephone-based "summons" is also essential to understanding this mobile phone related phenomena. In his original account (Schegloff, 1968), the ringing of the landline telephones is said to enact a form of social action by summoning a physically distant interlocutor to begin a new speech event (a telephone conversation). Relatedly, Humphreys (2005) has examined the subtle dilemmas that people in public spaces must deal with when they receive a phone call while already being concurrently engaged in a copresent interaction. Participants were found to engage in "dual front interaction," when participants answer a phone-based voice summons (phone call) and then utilize various nonverbal resources (e.g., waving hands, facial expressions) to simultaneously manage their involvement with their copresent interlocutor(s). Yet in contrast to such instances of voice-based summons (whether landline or mobile phone), an MTS affords the possibility of initiating new mediated interactions (via the mobile phone) without necessarily having to suspend or withdraw one's participation in the already in-progress, copresent activity in the same way. More recently, Licoppe (2010) has applied the notion of a summons to a broader class of notification technologies (e.g., alarms from clocks, audible notifications from mobile phones) that "stand for various chains of other events" and reshape the context in which they occur. The current article extends this work by documenting sets of communication practices through which interactants deal with and respond to notifications from mobile phones when 
they occur during an ongoing copresent encounter.

In sum, this article applies these three concepts—affordances, conversation analysts' notion of multiactivity, and what we refer to as the mobile text summons - to investigate how the affordances of mobile phones become relevant to, and are man- aged by, interactants when they receive a notification of a new text message in the course of an already in-progress stream of activity in copresent conversation. This focus lends further insight into how we may simultaneously interact with mobile technologies and one another in an increasingly technologically mediated social landscape. In the next section, we provide an overview of our data collection and methodological approach.

\section{Data and Method}

Our study primarily utilizes the methods of Conversation Analysis (Pomerantz \& Fehr, 1997; Sidnell, 2013), an inductive approach for examining naturalistic audio- or video-based field recordings of social interaction. Our data consist of a collection of 26 instances of MTS taken from over 15 hours of naturalistic video recordings of episodes of copresent conversation where participants happened to make use of their mobile phones. The recordings were collected by each of the authors from regions across the United States from 2011 to 2014. Although we did not have access to the activity occurring on the screens of participants' mobile phones, participant engagement with their mobile phones included observable behaviors recognizable as text- message exchanges (e.g., audible or visible summons notifications), marked shifts in attention toward the phone's screen and/or keyboard following an MTS, or explicit talk about a text message (e.g., announcements or questions from coparticipants). It is important to note that our analysis does not simply impose an a priori relevance of the technological affordances of these mobile phones onto the participants' conduct. Rather, we ground our claims about these features through the participants' ongoing demonstrable orientations to their 
mobile phones as consequentially relevant to an aspect of a conversational action (DiDomenico \& Boase, 2013; Raclaw et al., 2016).

In collecting the data, participants signed informed consent forms and were not explicitly told to use their mobile phones during the interaction. All recorded interactions were transcribed using the standard conversation analytic transcription conventions (Hepburn \& Bolden, 2013; Jefferson, 2004), which support the detailed documentation of production-related features of the conversations such as sound stretches, speaker overlap, laughter, in breaths and out breaths, and gestures and other nonverbal behaviors (see the appendix). After instances of the MTS were located and transcribed, these transcripts were used as tools during repeated viewings of the recordings to analyze the sequential organization of interaction and build collections of the phenomenon. Later on in the writing process, we further enhanced our transcripts by also incorporating Mondada's (2014a) transcription system, which has become increasingly prominent in studies analyzing the temporal dimensions of how participants coordinate the verbal and nonverbal aspects of their behavior (see the appendix). ${ }^{2}$

The analytic claims presented in this report, which center around verbal and nonverbal practices that were recurrently observed throughout the collection, were continually refined through repeated examination of the instances in the collection (see Pomerantz \& Fehr, 1997). Filtered images captured from select video recordings have been included alongside the transcripts (with white circles added around the mobile phones in particular cases) to provide a sense of the overall environment of the conversation and to highlight and contrast specific embodied behaviors as they are relevant to the production of a conversational action. Only a small selection of cases from our collection can be shown and analyzed to illustrate the general findings resulting from our analysis. 


\section{Analysis}

Throughout our collection, recipients of an MTS make use of a range of interactional resources to manage their participation in multiple speech events that potentially conflict with their displayed interactional attention. In the present analysis, we focus on how recipients of an MTS sustain their engagement with local activity or disengage from the copresent engagement in favor of shifting their attention to their mobile phone.

\section{Managing an MTS While Maintaining Recipiency in the Copresent Encounter}

The interactional use of mobile phones, especially in the presence of other coparticipants, presents rich scenarios in which to examine the dynamic emergence and management of discourse identities. Of particular relevance is the dynamic coconstruction of participants as speakers (who have the floor and are engaged in produc- ing some form of social action through their turn at talk) and recipients (who display their attention to the speaker's in-progress turn). In the two cases that follow, the MTS recipient engages in interactional work to attend to the summons while still maintaining a display of recipiency to the ongoing talk. For each, the recipient's enacted display of communicating with a mobile-mediated party may equate to a momentary suspension of participation (i.e., their recipiency) in the copresent encounter. More generally, our analysis of the cases offers a fine-grained look at how communication technology use during everyday conversations can create mundane interactional problems that participants manage depending on the in situ contingencies of the physical encounter.

Extract 1 below is taken from an interaction between three female college students who are sitting around the kitchen at one of their homes. Just prior to this segment, Amy asked Bri about her previous conversation with a mutual friend of theirs. Amy works to attend to the copresent engagement while also jointly managing the receipt of an MTS: 
Extract \#1 [MS01_artsy_fartsy_now_21-00]

* delimits gaze by Amy

- delimits other embodied displays by Amy

$M P=$ mobile phone

01 BRI: And he was like u:m: (.) he was like $0:: h$. (0.4) >He's

02 like $<$ well then we'll just hang out during the week

03

04

\section{BRI :}

amy:

06 BRI :

amy:

amy:

I was [like yeah ]

[( (AMY'S MP chimes))]

*we'll do like starbucks or someth*ing=

*gazes at phone------------------*

=or something •he was like (.) .hhh he was like (0.2)

-picks up MP•

•holds MP--->06.21
07 BRI: \#>he's like< what are you like artsy fartsy now, fig \#fig.1
08 He wa*s li (hh)ke \#>he was like<
amy: $\quad$ *gazes at MP--->08.21
fig \#fig.2
09 BRI: .hh videos an- and starbucks [and I was lik(hh)e I w(h) as]
10 CAT: [Hu:ah hehe
11 BRI: $\mathbf{l i \bullet k ( h ) e ~ h h [ h \quad ] ~}$
amy: $\quad$ grips MP with two hands--->11.21
12 САT: $\quad[. \mathrm{hhh}]$

13 BRI: I was like I love starbucks [Hehh] [he ]

14 CAT: [Hehe] [ha ha ]

15 AMY: [That's] what I say.

16 BRI: $\quad(0.3)$

18 though I had that creme brulee stuff $i$

19 (0.4)

20 CAT: That was goo: [d, *•ri:ght?

21 BRI : [But-

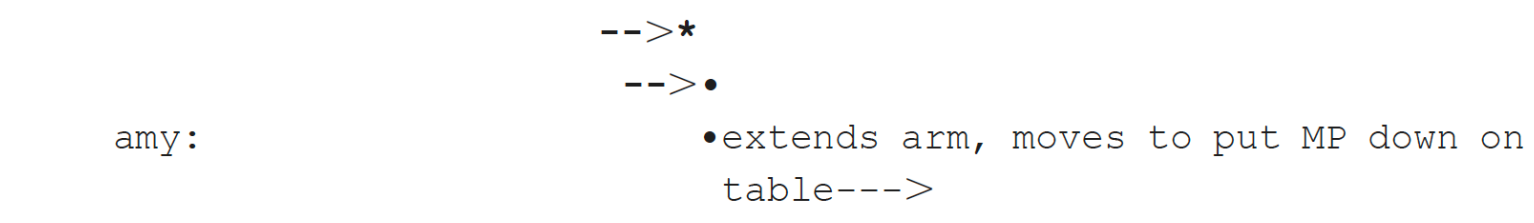

22 CAT: My (.) gingerbread thing was really good.

This Extract shows the in situ dynamics of how participants use their mobile phone (i.e., to receive and 
respond to text messages) while managing the interactional expectations and consequences of the local face-to-face interaction. In lines 01 to 08 , Bri is producing her telling about the mutual friend known to her and Amy. Throughout this course of action, Amy visibly embodies her discourse identity as a recipient by direct- ing her head and eye gaze toward Bri (who is seated to Amy's immediate right). Prior conversation analytic research has shown how gaze is used in concert with verbal action as a means of managing the flow and organization of talk (e.g., Ford, 2008; Goodwin, 1980, 1981, 1984; Lerner, 2003; Rossano, 2012; Stivers \& Rossano, 2010), and Goodwin's work in particular was foundational in examining the ways in which recipients to an ongoing activity display their recipiency through continued gaze toward a current speaker.

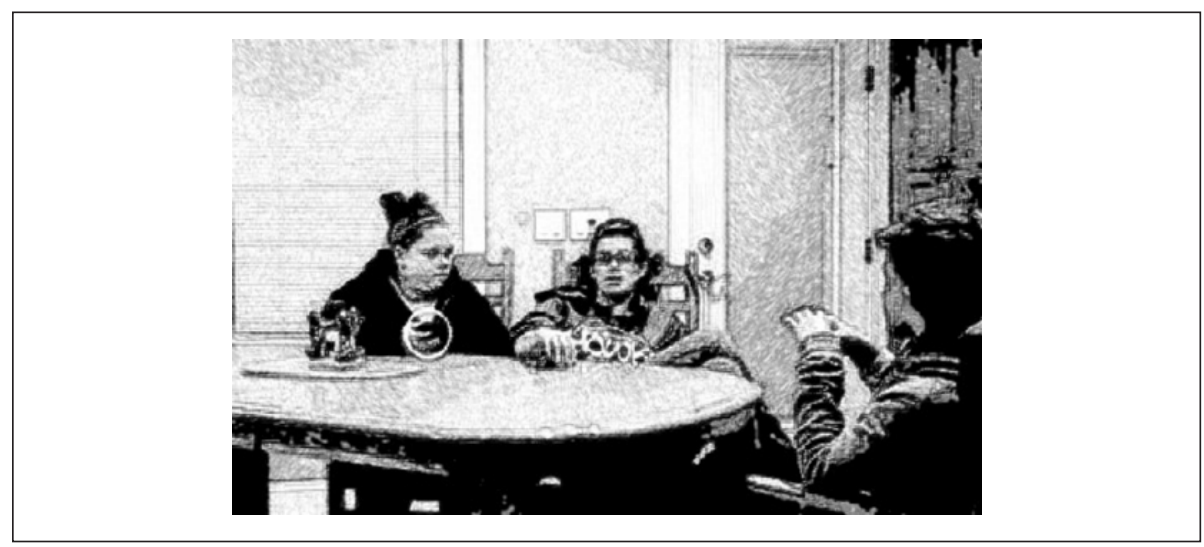

Figure 1. Amy embodies recipiency with her mobile phone in hand (line 06).

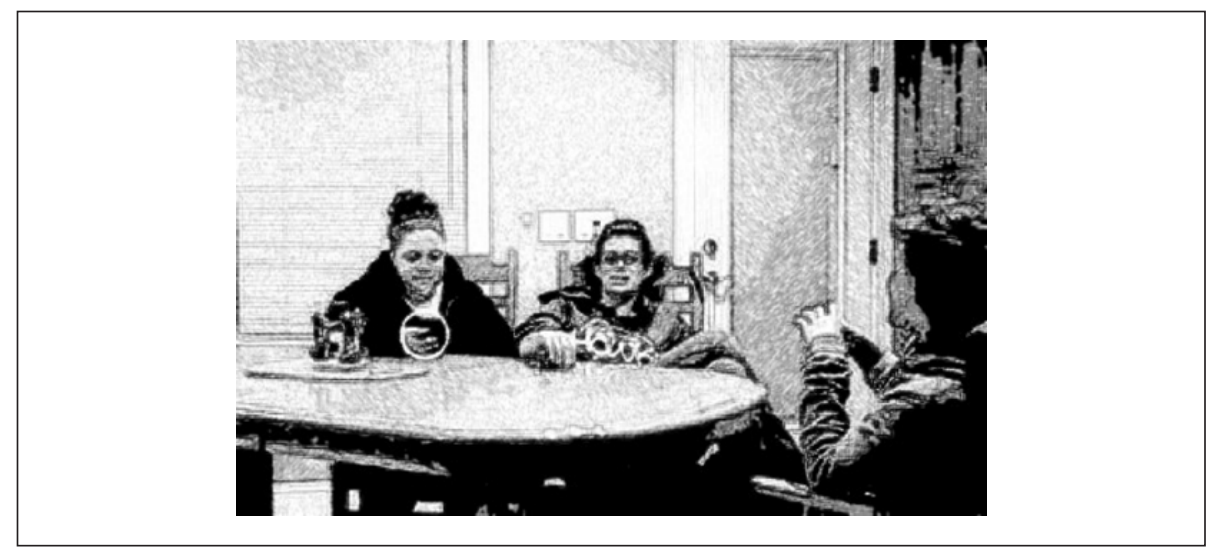

Figure 2. Amy gazes down toward her mobile phone (line 08). 
While Amy visibly attends to the telling, one of her hands is resting on her lap and her other hand is on the table near her glass of water and not far from where her mobile phone (referred to as "MP" in the transcript) is resting on the table. In line 04, Amy's mobile emits a chime indicating the receipt of an MTS. Amy orients to this chime by briefly turning her head and partially directing her gaze away from Bri (whose telling is still underway). Even as Amy proceeds to reach for her mobile phone and prepares to access the text message (see Figure 1), she maintains the direction of her gaze toward Bri until line 08 , when she directs her gaze at her mobile phone (presumably to access and read the text message). As Bri reports the friend's speech from the narrated event (lines 6, 7), Amy continues to gaze at her until Bri's turn reaches a point of possible syntactic, prosodic, and pragmatic completion (or transition relevance place, see Clayman, 2013; Sacks, Schegloff, \& Jefferson, 1974) at the end of line 7.

Around line 08, Amy shifts her gaze down toward her mobile phone (see Figure 2) just as Bri recycles the quotative "he was like." At line 09, Bri goes on to produce reported speech (Holt, 1996) with some interspersed laughter that invites shared laughter from her storytelling recipients. While Cat joins Bri in producing audible laughter at line 10, Amy produces a smile that orients to the laughability of Bri's telling, but Amy does not herself laugh. Amy then brings up her left hand to interact with her mobile phone using both hands (line 11), presumably to construct a text message response. As Amy does so, Bri produces an assessment followed by laughter that may be closing-relevant ("I love Starbucks"). Cat responds with further laughter, while Amy, still gazing at and typing on her mobile phone, produces a response in line 15 with "That's what I say." This response aligns with Bri's assessment and stance toward the coffee brand. Thus, Amy manages multiple streams of activity as she dis- plays her alignment with the current speaker's course of action while deploying bodily resources to attend to her involvement with her mobile phone. 
From lines 17 to 18 , Bri goes on to unpack her reported assessment of the coffee brand, and Cat responds at line 20 with a positive assessment of the referent Bri introduces at line 18 (the "creme brulee stuff") that explicitly invites Bri's agreement through its formulation as a tag question ("That was good right?"). In overlap with Cat's talk, Bri begins to formulate a new unit of talk at line 21 that is subsequently abandoned ("But-") but nevertheless mobilizes Amy to gaze up from her phone to now direct her visible attention toward Bri. In overlap with Cat's continued production of her tag question at line 20, Amy then shifts her mobile phone away from her body (leaving it less visually accessible) while still holding onto it (line 21) and resumes a fuller bodily engagement with the copresent interaction as she nods in agreement with Cat's assessment. In this way, the affordances of ordinary conversation support Amy's involvement across concurrent face-to-face and mediated activities. Amy's discourse identity as a recipient in the copresent storytelling affords her more interactional leeway to adopt subordinate side involvements she can engage in nonverbally such as, in this case, checking an MTS from a noncopresent interlocutor. ${ }^{3}$ Amy's use of verbal and nonverbal resources thus allow her to simultaneously manage her discourse identity as a recipient in the local face-to-face interaction and the technologically mediated exchange occasioned by the MTS.

In addition, an affordances perspective toward technology provides insight into what makes the management of these different concurrent activities possible. In the beginning of the Extract, Amy's delay in picking up and attending to her chiming mobile phone, as well as her delay in composing a response by typing, is enabled by the affordances of her mobile phone. Text messaging, as an asynchronous communication technology, is typically used between people who lack shared spatial and temporal circumstances. In the current example, these capacities are what allow Amy to both delay and comanage the activities of checking and responding to her mobile-mediated interaction. It should also be pointed out that Amy's conductrelated to managing her recipiency in the face-to-face interaction is 
not accessible to her mobile-mediated interlocutor, thus preventing them from hearing (or seeing) Amy's copresent involvements as a barrier to communicating. In contrast, if Amy were to have received a voice-based summons on her mobile phone (i.e., a phone call), she would have to treat it as a bid to enter a synchronous interaction that leads her to face suspending her recipiency in the copresent conversation. In sum, this example shows how speakers make use of the affordances of both ordinary conversation and mobile phones to maintain recipiency across both copresent and technology-mediated inter- actions. Furthermore, it serves as a window into seeing the way communication technologies can serve as further interactional resources that help facilitate the management of the complexities of communication across multiple modalities.

Interactants may also orient to an incoming MTS by temporarily suspending their recipiency in the copresent interaction and displaying their primary involvement with their mobile-mediated interaction. Such moments demonstrate how embodied engagement in the face-to-face domain can serve to ratify a participant's discourse identity in an established activity. The next extract illustrates how a recipient may retract or suspend their recipiency to disengage with the copresent interaction while they receive, checks, and constructs a response to a MTS. Occurring just as Extract 1 ends, the participants (Amy, Bri, and Cat) continue their assessment of coffee products. Though Extract 1 ended with Amy shifting her gaze away from her phone and up at Bri, Amy shifts her gaze to Cat (the now- current speaker) shortly after Cat begins to speak at line 28 . 
Extract \#2-[MS09_facebook_21-35_SD]

* delimits gaze by Amy

- delimits other embodied displays by Amy

$\triangle$ delimits additional embodied displays by Amy

$M P=$ mobile phone

CAT: $\quad$ *My (.)

*gingerbread thing was really good.

amy: *gazes down at $\mathrm{MP}^{\star}$

amy :

*gazes at CAT--->22.46

23

- Minus the $\Delta$ fact

- I couldn't sleep last night. $\triangle$

amy: $\quad$ retracts arm, pulls $\mathrm{MP}$ toward herself•

amy:

-holds MP with both

hands--->23.65

amy:

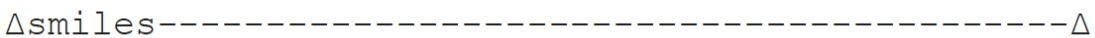

((Iines 24-42 omitted))

CAT:

Li (hh) ke (0.2) I'm on Facebook there's like ni:ne people

44

45

46

o[n Face ]book?

[( (AMY'S MP chimes) ) ]

CAT: $\quad>I^{\prime} m \star l i k e<$ yeah you $=$

$-->\star$

amy: $\quad$ *gazes down at MP--->46.65

CAT: =know it's late when $t$ [here's only nine people]= 


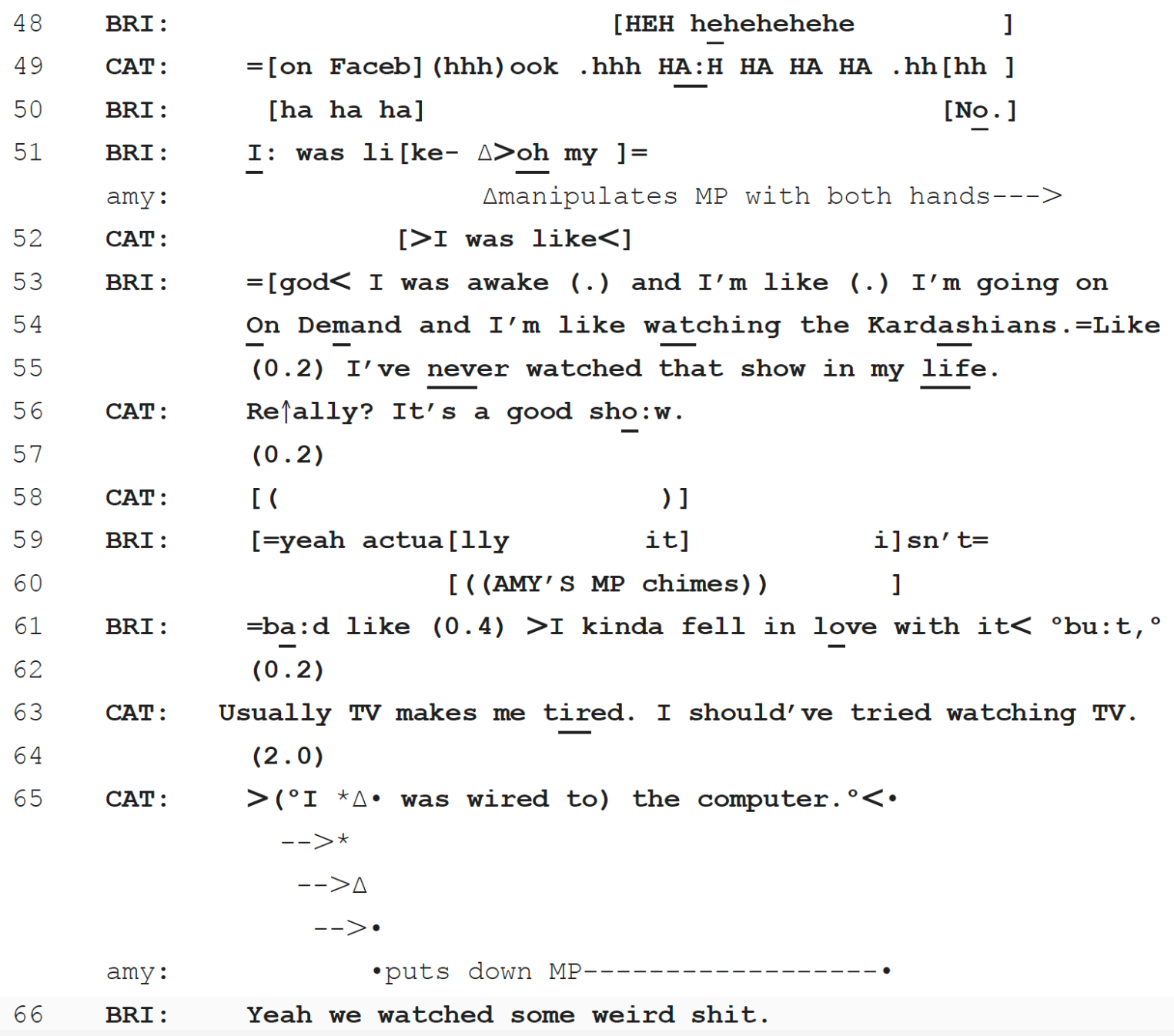

This excerpt shows how an interactant may treat the interaction initiated by the MTS as her primary, exclusive engagement while withholding displays of recipiency to the local copresent activity. In lines 22 and 23, Cat produces a positive assessment of her coffee drink immediately followed by a playful complaint regard- ing the effect of its caffeine content on her ability to sleep that night. From lines 23 to 44, Cat is reporting her activities during her sleepless night as Amy and Bri continue to respond with laughter. Throughout this spate of talk, Amy continues to gaze at Cat (the current speaker), only ceasing to do so as Amy's mobile phone emits a chime at line 45, marking an incoming MTS. Immediately following, Amy turns her gaze toward her phone (line 46) and ceases the stance-relevant laughter practices that she had conducted in the moments prior, adopting a visibly and hear- ably neutral 
stance by refraining from joining the choral laughter that erupts among her interlocutors a few moments later at lines 40. In line 51, as Bri initiates a second story (Ryave, 1978; Sacks, 1992a; Sacks, 1992b; cf. Mandelbaum, 2013) about her own experiences with sleeplessness, Amy begins typing (ostensibly a response to the incoming text message). As Bri continues her telling, Cat visibly sustains her recipiency through the use of gaze, affective facial expressions, and stance-relevant verbal responses, enacting surprise and producing an assessment in line 56. In line 59, Bri responds to Cat's assessment through a second assessment. During and after this turn (lines 67-70), Amy engages in several mobilerelated activities. In line 60, as Amy types on her phone, the device emits another chime.

As this extract shows, how participants treat an MTS can shape how they man- age their discourse identity in the local conversation. Here, the MTS recipient proceeded to interact with her mobile phone in a way that suspends her display of recipiency in the copresent interaction. As this interaction involves three parties, however, Amy is provided greater interactional leeway in the degree of participation that may be expected of her in the conversation. As she utilizes this opportunity to engage more directly with her mobile phone, her cointerlocutor continues to maintain recipiency to the copresent engagement. This suspension of copresent participation is thus made possible via the affordances of social interaction, specifically multiparty talk.

Extracts 1 and 2 each show how interactants make use of different interactional resources to manage their recipiency to both their copresent and mobile-mediated interactions. In Extract 1, Amy attends to her mobile phone with her eye gaze while intermittently deploying other bodily resources, including verbal and nonverbal cues, to manage her participation as a recipient to her interlocutor's telling. In contrast, in Extract 2, Amy attends to her MTS with minimal effort toward maintaining her recipiency to the activities in the face-to-face conversation. In each of these cases, the affordance of asynchronous, text-based communication of the mobile phone allows MTS recipients to attend to the 
actions alerted by audible MTS while also managing their participation as recipients in the copresent encounter. In the next section, we shift our focus to instances where the MTS recipient occupies speakership when a notification chime occurs.

\section{Managing an MTS While Maintaining Speakership in the Copresent Encounter}

Outside of enacting recipiency, participants may also adopt primary speakership within the immediate framework for participation in the copresent encounter. In this role, interactants can produce multiunit turns, or turns at talk consisting of multiple successive turn-constructional units (see Clayman, 2013; Sacks et al., 1974), as is typically the case with storytelling (Mandelbaum, 2013) or advice-giving activities (Heritage \& Sefi, 1992). Fellow participants enact their recipiency to the speaker's extended, multiunit turn at talk by using interactional practices that display their understanding that the current activity requires more than a single turn-constructional unit and, relatedly, display an understanding that the ordinary system of turn taking in conversation must be temporarily suspended until the extended turn is finished. ${ }^{4}$ Participants who receive an MTS while acting as the current speaker are presented with an interactional problem as this discourse identity comes with a range of normative expectations related to the embodied production of the ongoing activity (including eye gaze and bodily orientation; see Goodwin, 1981). Thus, how speakers go about managing their engagement with mobile phones during a copresent conversation may reflect these copresent interactional relevancies.

Extract 3 is taken from a conversation between two university students, Faye and Julie. The two have been discussing Faye's recent assignment for a photojournalism class, in which Faye interviewed a mutual friend known to both participants. Faye had recently presented a portion of the interview to her class and disclosed private information about the interviewee, who is now angry with her for making this information public. As the Extract begins, Faye is engaged in telling her side of the story as part of a "troubles-telling" 
sequence (Jefferson, 1988; cf. Mandelbaum, 2013). At line 17, Faye continues an indirect complaint about her photojournalism professor, asserting that the professor's unclear instructions for the assignment are to blame for her overly candid presentation.

\section{Extract \#3 (MS04 On the Spot) \\ * delimits gaze by Juliel \\ - delimits other embodied displays by Julie \\ + delimits gaze by Fay \\ $\triangle$ delimits other embodied displays by Fay \\ $M P=$ mobile phone}

17 FAY: Yea:h he never said that we were presenting them at a: $: 11$. $(0.4)$

19 FAY: So like I was o[n the spo: $t$,

20 JUL: [个Yea:,

21 JUL: That's harder because you don't have things planned out

22 to sa+:y?

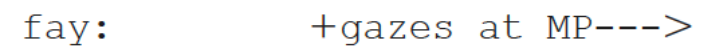

24 JUL: tsk like maybe that's a s:tep in journalism school that

25 you need to lear:n, (1.0) whi:ch, (0.5)

25 FAY: + Mmhm:

fay: +nods head--->

26 JUL: $0: N$ the spot which facts you $\frac{\mathrm{ca}: \mathrm{n} \triangle}{-->\Delta}$ [sa+:y.*

fay:

jul:

28

29

JUL:

fay:

fig

jul:

fay:

fay:

30 JUL :

$$
(0.2)-->+
$$

[ ( (JUL's MP vibrates))

+ gazes at MP--->

*gazes at MP-->

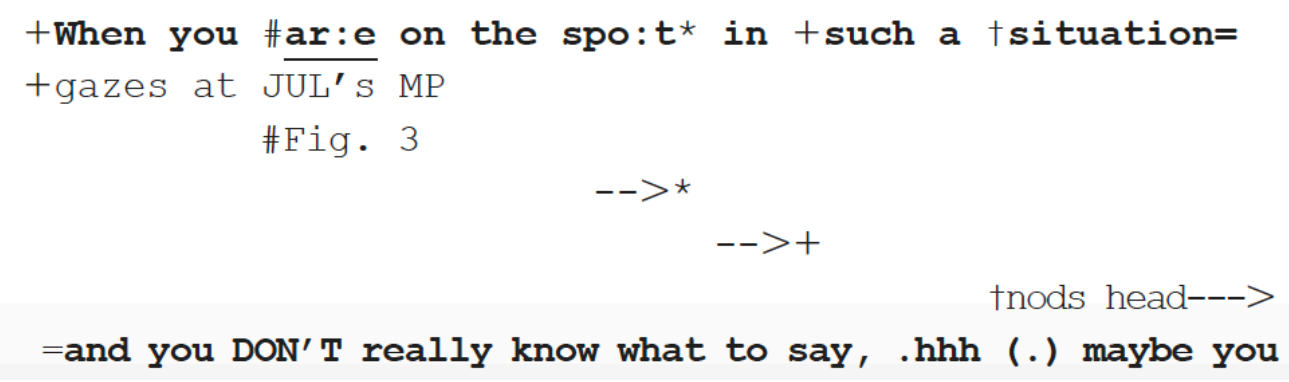


31 need to develop a journalism skill that's $\triangle$ where [you

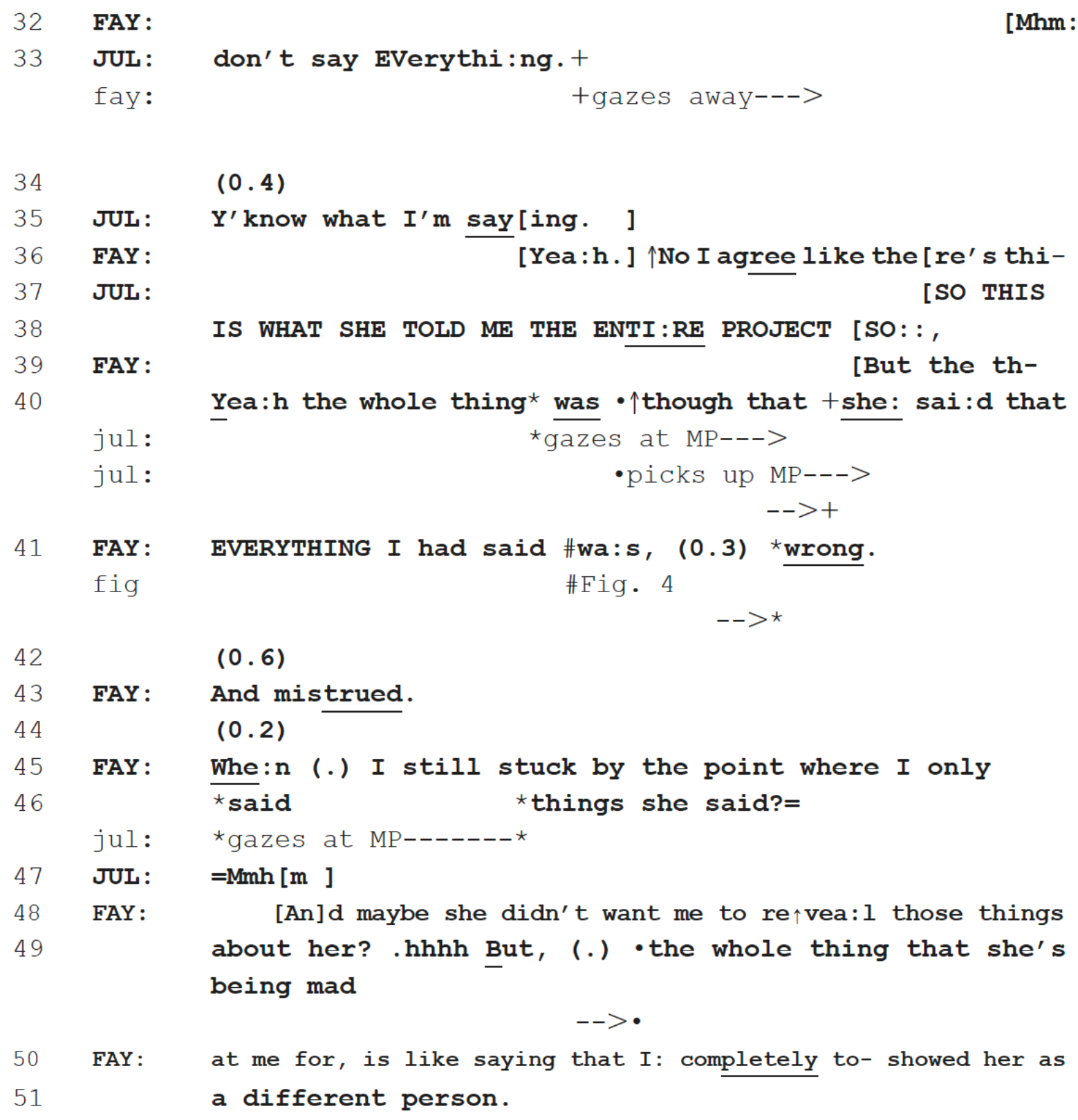

At line 21, Julie responds to Faye's troubles-telling by offering advice, suggesting that Faye may need to further develop the skills needed to respond in a more moderate and care- ful manner when placed "on the spot" to discuss her work. Julie's enactment of advice- giving is coconstructed by both participants as being a multiunit turn, where the ordinary system of turn-taking is typically temporarily suspended and Julie is given primary rights to the speaking floor until her course of action is complete (see Mandelbaum, 2013; 
compare Heritage \& Sefi, 1992). Faye displays her recipiency throughout this activity by limiting her contributions to only minimal responses and head nods from lines 25 to 33 . Following the silence at line 23 , Faye turns her head and eye gaze toward Julie, further enacting her con- tinued recipiency to Julie's ongoing extended turn at talk. In addition, for much of the inter- action, Julie organizes her silences as intraturn pauses (as in line 25) at points in the talk where her turn cannot be heard as either syntactically or prosodically complete, a common turn-maintenance strategy employed by current speakers (Sacks et al., 1974).

It is during this multiunit turn that Julie becomes an MTS recipient, and her discourse identity as current speaker is relevant to how she manages the incoming summons. The MTS occurs at line 27 as Julie's mobile phone, which has been resting faceup on the table in front of her, begins to audibly vibrate. The MTS occurs in the midst of Julie's ongoing talk, and as Julie's turn comes to a point of projectable completion, both Julie and Faye direct their head and eye gaze down to look at their respective phones that are resting on the long table in front of them. Following a short silence, at line 29, Julie resumes the advice-giving activity with her gaze still directed toward her phone, and as Julie begins to speak, Faye shifts her gaze toward Julie's phone as well. ${ }^{5}$ Shortly after Julie begins to speak, she raises her gaze from her phone to gaze at Faye, and Faye subsequently shifts her gaze up from the phone to establish mutual gaze with Julie as Julie's turn continues.

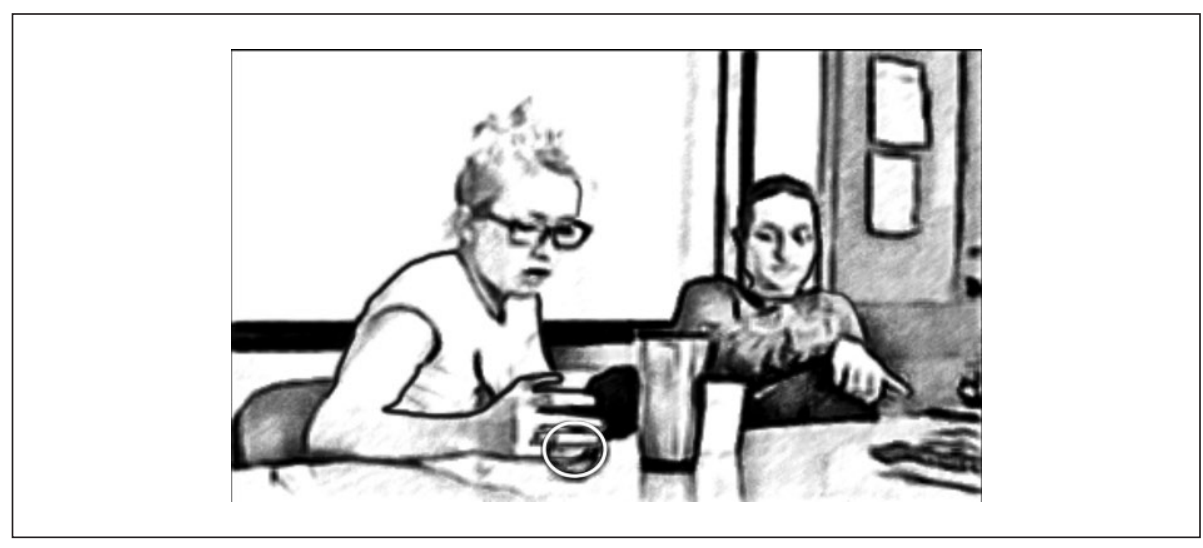

Figure 3. Julie and Faye gaze at Faye's mobile phone (line 29). 


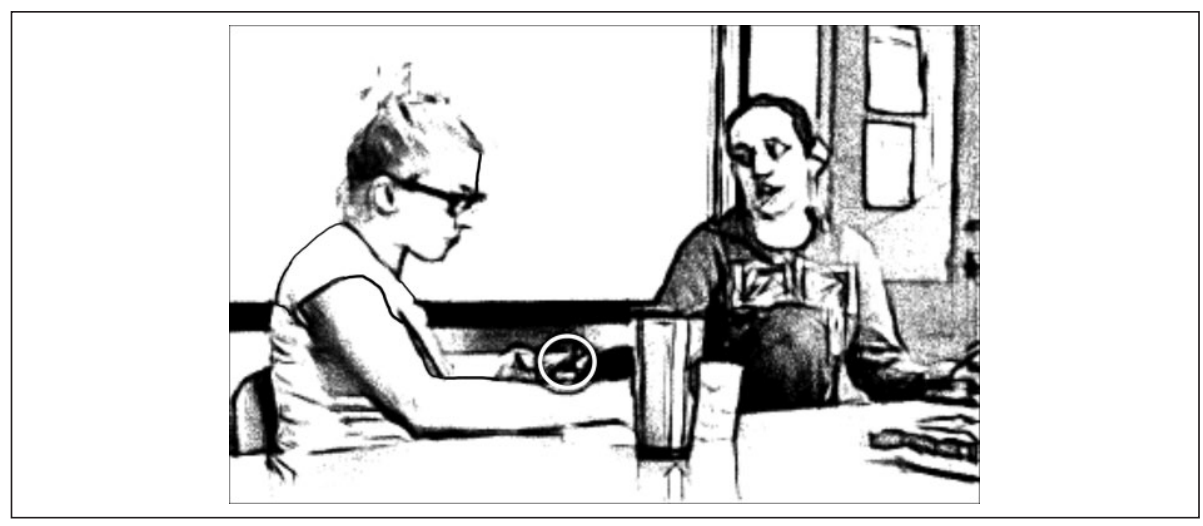

Figure 4. Julie gazes at her mobile phone as Faye speaks (line 41).

Through careful attention to the moment-by-moment unfolding of the interaction, we thus see that the incoming MTS invites a series of embodied responses from both participants while offering only a minor impediment to the progressivity of the talk. The audible vibration of the initial MTS is attended to by both participants as they first direct their gaze to their respective phones before settling their collective attention toward Julie's mobile phone, which emitted the MTS chime.

The participants gaze at the phone only briefly (line 28) before the current speaker, Julie, returns her gaze to her recipient, Faye, and the two once again establish their mutual gaze as Julie continues to speak during the advice-giving activity. This activity culminates at line 30 , as Julie offers the suggestion that Faye may need to develop the journalistic skill to appropriately handle being placed "on the spot" by her professor. Though this action invites Faye's agreement as a preferred response (Pomerantz, 1984), it is followed by a beat of silence as Faye gazes away from Julie, thereby pro- jecting her disagreement (Haddington, 2006; Rossano, 2012). At line 35, Julie explic- itly invites Faye's response through an understanding check ("Y'know what I'm saying"), and Faye responds with a proforma agreement (Schegloff, 2007) at line 36 that initially claims her agreement but goes on to disagree with Julie as it is followed by a "my side" telling (Pomerantz, 1980) at line 39.

As Julie shifts out of current speakership and moves into the role of recipient to Faye's my-side telling, Julie directs her gaze back to her mobile phone while Faye is still in the midst of an ongoing turn 
now additionally lifting it to bring it closer to eye level, and formally attends to the MTS by visibly beginning to read the text. Having now become a recipient within the interaction, the organization of Julie's attention to her mobile phone (as she finally attends to the MTS) is much the same as that seen in the prior two Extracts. In the midst of Faye's talk at line 40, Julie shifts her gaze down to her mobile phone and subsequently picks it up with one hand to move the device into her field of vision. Julie's gaze remains on her mobile phone until Faye produces an intraturn pause at line 41, a move that successfully invites Julie's gaze (cf. Goodwin, 1980). Julie thus works to coordinate her embodied attention to her mobile phone along with her attention to Faye. In sum, this case shows how someone occupying the speaking floor can delicately manage the receipt of an MTS, and then later on once they have relin- quished speakership, renegotiate their displayed involvement toward the mobile phone. A similar display of embodied responses to an incoming MTS occurs in Extract 4, taken from the same conversation between the participants from Extracts 1 and 2. This instance involves only Amy and Cat, as Bri has since left the room. Prior to the excerpt, Amy had expressed interest in beginning psychotherapy sessions, and she has asked Cat a series of questions about her own experience in therapy. As the Extract begins, Cat is describing her initial motivation for seeing her therapist. At line 3, Amy responds with her own reasons for desiring therapy: to come to terms with being gay and to address issues stemming from her parents' divorce. At line 5, Amy then begins to for- mulate a multiunit telling about a recent incident between her and her mother. As Amy's telling is still in progress, she receives an incoming MTS at line 7. 
Extract \#4 (MS14 Being Gay)

* delimits gaze by Amy

- delimits other embodied displays by Amy

+ delimits embodied displays by Cat

$M P=$ mobile phone

CAT: like I was just like a mess [:

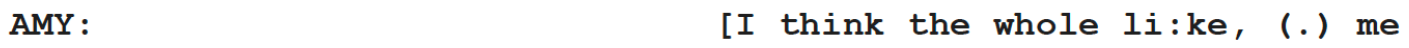




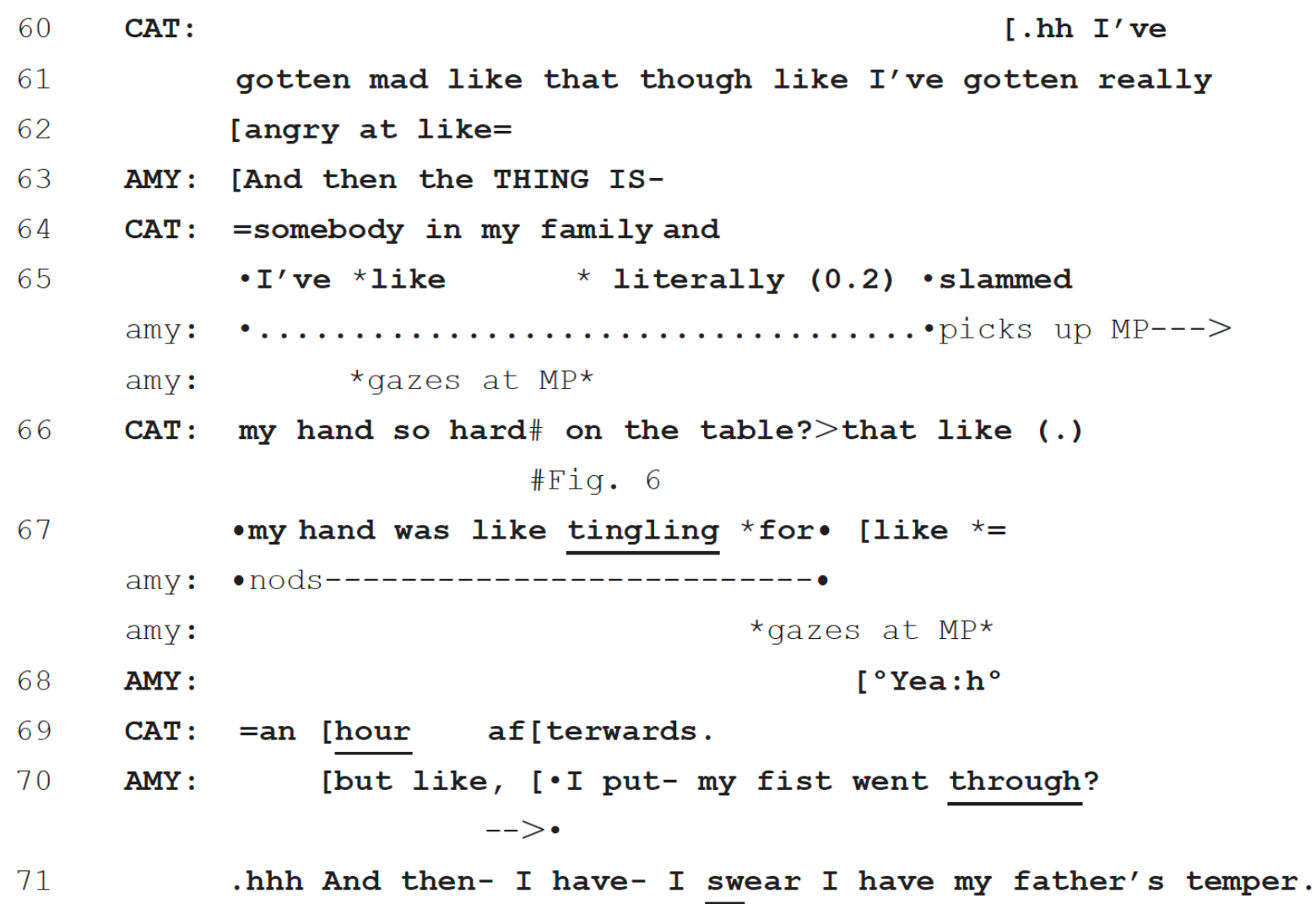

There is a short pause following the MTS during which Amy maintains her bodily orientation toward Cat but shifts her eye gaze down toward her phone, which is resting on the dining room table in front of her (line 6, see Figure 5). After return- ing her gaze to Cat, Amy momentarily abandons her inprogress storytelling to provide a further preface to the story (lines 8 to 11) and then resumes the telling proper (omitted from the transcript). The climax to Amy's narrative, in which she punches a door in anger, is prefaced at lines 54 to 56 and announced at lines 57 to 59 . At lines 60 to 67, Cat prefaces and tells a second story describing how she has also physically expressed her own anger.

The preface to Cat's story is produced in partial overlap with Amy's talk from line 59, and at line 63 Amy attempts to return to her in-progress telling, raising the volume of her voice in a competitive bid for speakership. However, Amy abandons this action at line 63 through a hearable glottal cutoff while also visibly abandoning this bid for speakership at line 65 as she shifts her body toward her 
phone in preparation of picking up the device. As in Extract 3, this visible shift in attention toward her mobile phone occurs only as the now-current speaker (Cat) is already midway into the production of a turn-constructional unit at line 65. As Amy's body torques toward her phone, she briefly shifts her eye gaze away from Cat and toward her phone before returning her gaze to Cat and lifting the phone to bring it into her field of vision (see Figure 6).

Shortly after Amy picks up her phone, she further displays a shift toward recipiency to Cat's ongoing telling as Amy delivers a series of head nods (line 66) followed by another brief glance toward her phone. As we have seen in prior excerpts, embodied displays of engagement with one's phone (via eye gaze and lifting/holding the device within one's field of vision) are typically reserved for speakers who are recipients to the ongoing talk rather than primary speakership, and we argue that Amy's visible engagement with her phone at line 65 is yet another way that Amy displays her move to recipiency as Cat begins to speak.

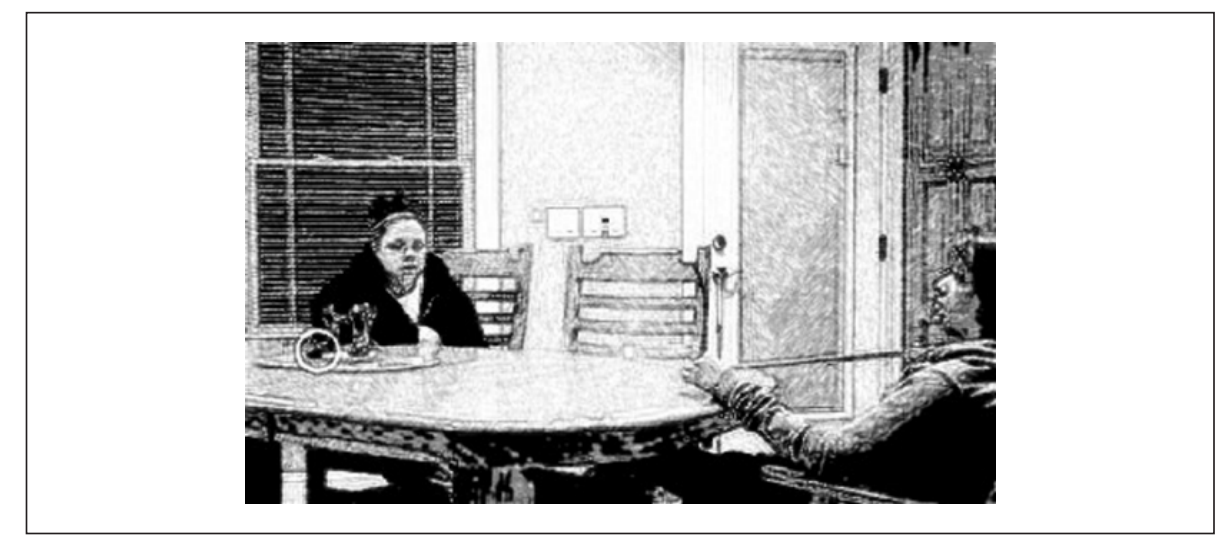

Figure 5. Amy's side glance toward hermobile phone following an audible mobile text summons (line 06). 


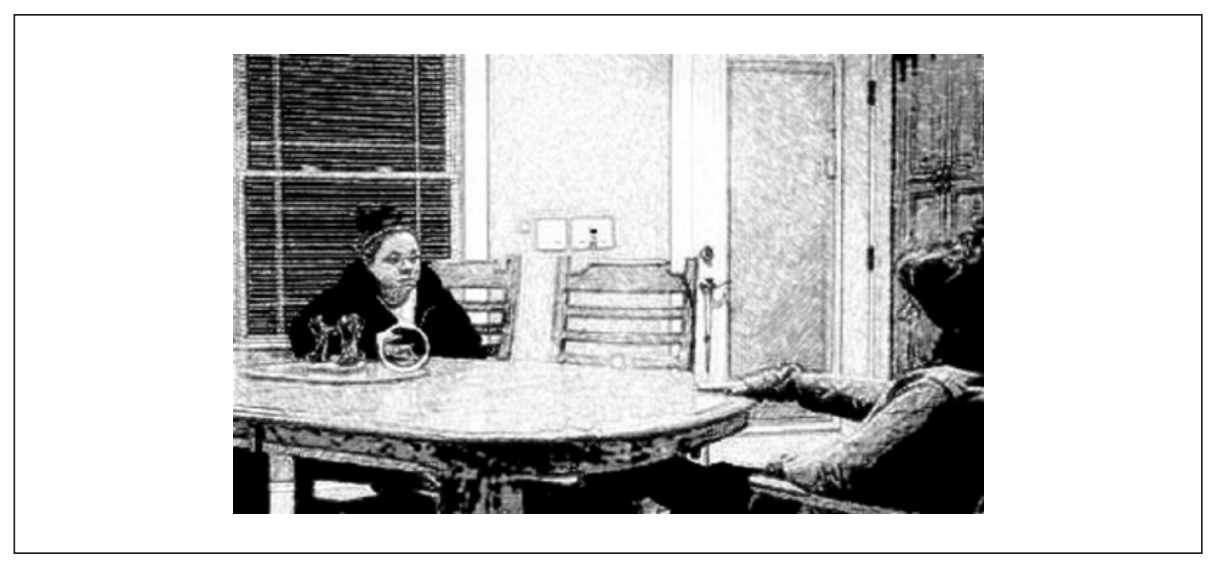

Figure 6. Amy gazes at Cat while holding her mobile phone in an accessible position (line 66).

At line 68, Amy produces an agreement token (“yea:h"), a move that may project her shift back to active speakership at line 70 as she returns to her previously aban- doned telling. This return to her prior telling is also projected through embodied means as Amy returns her mobile phone back to the table (and thus out of her non- peripheral field of vision) at line 68. Both of these moves constitute a multi-modal display of Amy's projected return to speakership. As in Extract 3, we see that the current speaker concludes her speakership prior to attending to the MTS. More specifically, in Excerpt 4, Amy cedes her role as current speakership following a failed bid for the floor after the overlap at lines 62 to 63. Shortly after, Amy gazes at her phone, takes her phone in hand, and places it within her field of vision before intermittently gazing at both her mobile phone and at Cat, who is at that point the current speaker (lines 65-67). As previously noted, we argue that Amy's shift in visible attention toward her mobile phone in fact displays an embodied shift out of the role of current speaker and into the role of recipient to Cat's ongoing talk. In summary, these cases show how MTS recipients can manage precisely when and how they should attend to their MTS while dealing with the communicative contingencies of the local discourse identities in the conversation. 
A further phenomenon observed in our data involved participants incorporating the MTS-prompted action into the ongoing progression of the copresent interaction. It is important to remember that, as a type of summons, the mobile phone serves as a vehicle through which a remote party initiates another, potentially competing, form of (mediated) interaction. From the perspective of the summons recipient, one possible way of responding to this summons is to essentially col-lapse the interactional boundaries between the copresent encounter and their mobile-mediated involvement (to which physically copresent interlocutors generally have only minimal visible access). As a result, the lines between the interactional contingencies and discourse identities of both interactions become blurred. We can see this phenomenon illustrated in Extract 5 below. In this segment, three college-age friends, Ann, Beth, and Cam (see Figure 4), are spending time together in one of their bedrooms. For much of this conversation, Cam participates as both a speaker and a recipient while he is also engaged in trying on a necklace from Ann's jewelry collection. Notably, the talk in this extract is located within a different sequential context than those seen in prior extracts. While each of the prior cases have examined responses to an MTS occurring during a multi-unit telling in which a single participant serves as primary speaker for an extended portion of the talk, the talk in Extract 5 occurs while the speakers are in the midst of a joking complaint sequence in which each speaker collaboratively contributes to the activity's progression. A few seconds into the Extract, Cam reaches off camera for his mobile phone after it emits a series of chimes. He then deals with the summons by reporting its content for his copresent participants: 
Extract \#5 [MS02_finish_your_resume_02-01]

* delimits gaze by Cam

- delimits other embodied displays by Cam

$\triangle$ delimits additional embodied displays by Cam

+ delimits embodied displays by Beth

$M P=$ mobile phone

11 BET: What we can't curse? Well then we \#can't have fig \#fig.7

12 regular co[nversation. ]

13 CAM: [Heh[e (right) ]

14 ANN : [hhHAHA ]hahahe

15 BET: heu hah [aha ]

16 CAM: [It's] never gonna happen. We never

17 hav[e normal conversation]

18 [((CAM'S MP CHIMES))]

19 CAM: *where people don't cur:se.* Like what?

*gazes at MP on desk------*

20 CAM: H[eh ]

21 ANN : [Tha-] well no- 


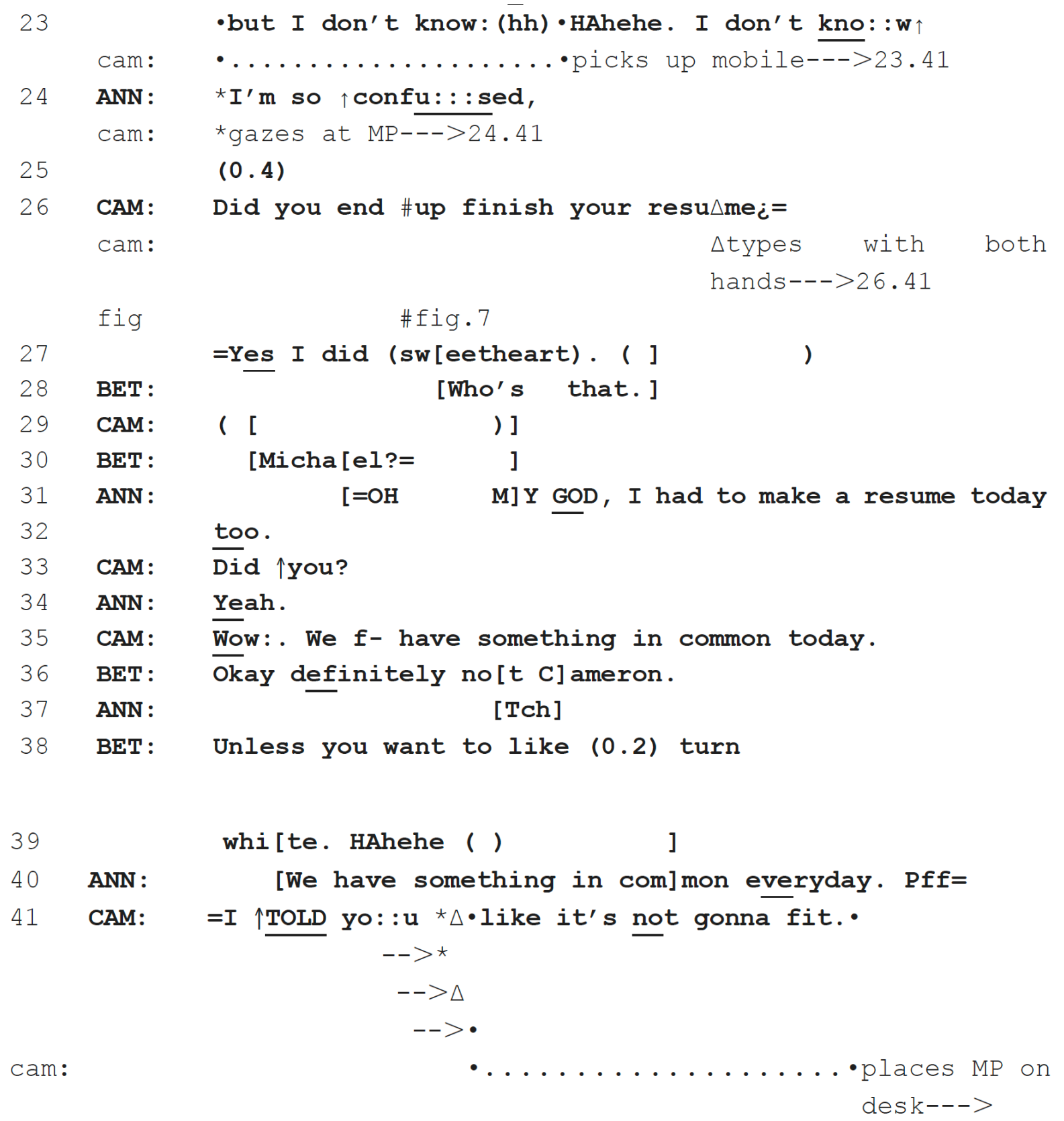

In this instance, we see how a participant's mobile phone can be used as an additional resource for producing social actions for copresent interlocutors. Just prior to the start of this Extract, Ann had jokingly sanctioned Cam for his choice of the word "bitch" while video recording. In lines 11 to 12, Beth launches a complaint about a (incorrectly) presumed research-related restriction concerning curse words. Following shared laughter from all participants, Cam rejects the idea of such a restriction in lines 16 to 17 . At line 
17, just as Cam is coming to what is the projectable end of his turn-constructional unit, his mobile phone chimes on top of the nearby desk. As Ann begins to provide a more serious account for her earlier critique of Cam's choice of language (lines 21 - 23), Cam begins to release his grip on the necklace Beth is pulling toward her, ${ }^{6}$ a disengagement with the copresent embodied activity that projects Cam's shift in gaze toward his mobile phone on a desk nearby. Cam then grabs his mobile phone (line 23) and brings it into his field of vision. By line 24, just as Ann is producing "I'm so confused," Cam is now fully attending to the mobile phone by directing his gaze down at the device.

After a brief gap in line 25 during which Cam is presumably silently reading the incoming text message, Cam then begins to read the text message aloud in line 26 ("Did you end up finish your resume?"). As he reads the message aloud, Ann and Beth both simultaneously direct their gaze toward him. Then, in line 27, Cam begins reporting aloud what he presumably begins to type into the mobile phone as a response to the message he received ("yes I did sweetheart," see Figure 8). At line 28, Beth attempts to shift the group's collective attention to the text message as she asks "Who's that." Beth then leans toward Cam in an attempt to renew the prior embodied activity by putting the necklace around his neck. The remainder of this segment features the other participants asking Cam about his announced text-mes- sage response as his explicit reference to resume writing becomes topicalized in the subsequent talk.

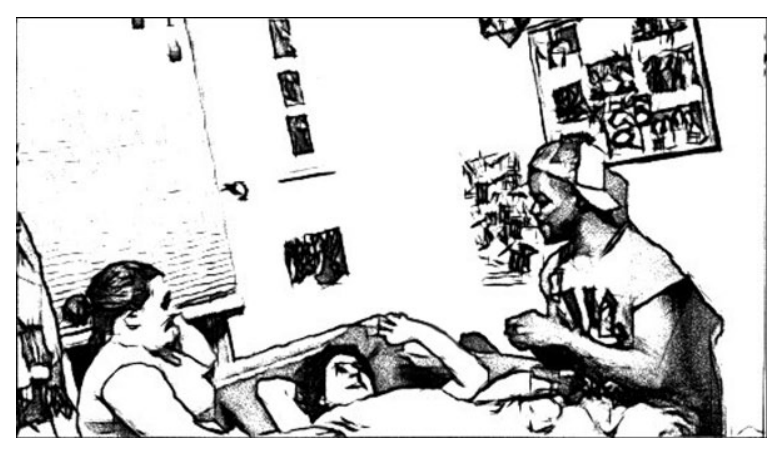


Figure 7. Ann, Beth, and Cam prior to the mobile text summons chime (line 11).

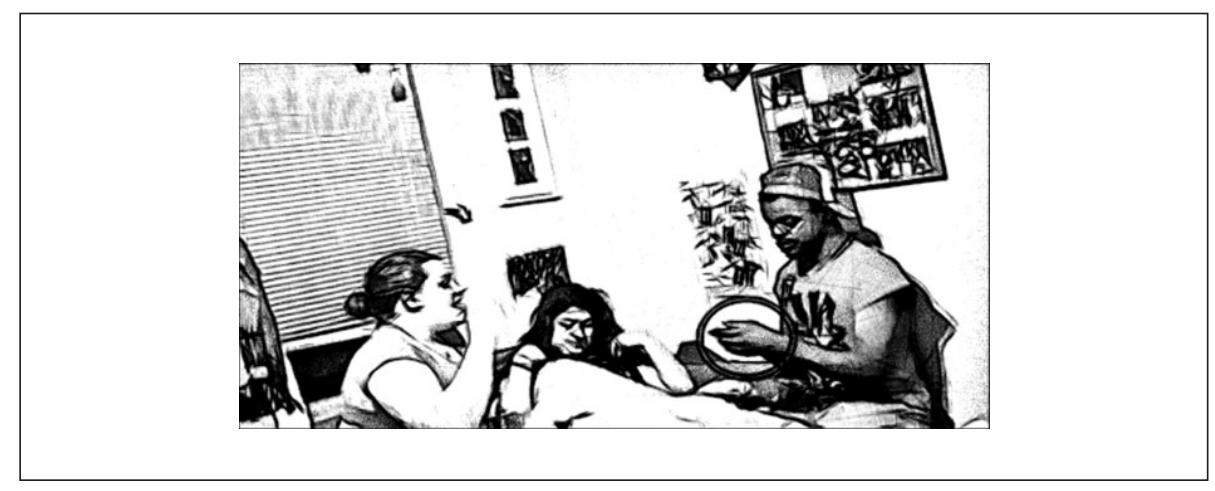

Figure 8. Cam reads the text message aloud (line 26).

In sum, this final case shows a further way in which participants may attend to an MTS while also being concurrently engaged in a copresent interaction. Following the MTS — which occurs as Cam is in the midst of speaking - Cam briefly directs his gaze toward the mobile phone, but does not begin to interact with the phone to attend to the summons. Instead, he displays his active recipiency toward Ann's ongoing turn as he continues to gaze toward Ann and Beth (who are seated next to one another) until the transition relevance place following line 24 . We saw a similar social organization occur in Extract 1, and it is one that occurs throughout our col- lection of instances. However, in contrast to Extract 1, the MTS (and its locally enacted response) is dealt with in a way that more overtly shapes the trajectory of the copresent conduct by incorporating the content of the text message as a spring- board for a focal action in the local speech event. Cam makes the MTS interactionally relevant as he reads the message aloud and then proceeds to read aloud the text-message response that appears to be constructing. Such a move works to essentially collapse the interactional boundaries between the ongoing copresent encounter and the mobile-mediated interaction by topicalizing the mobile phone activity. Overall, the Extract demonstrates an additional practice for leveraging verbal and nonverbal resources, most notably the practice of orally reporting text messages, in order to manage one's discourse identities across both interactions. 


\section{Discussion}

In this article, we examined how interactants manage the receipt of incoming mobile text messages during the course of an ongoing face-to-face encounter by utilizing the affordances of mobile phones as well as a range of verbal and nonverbal resources (e.g., body position, eye gaze) that are available to interactants. The affordances of the mobile phone, namely those related to asynchronous text-based interaction, provide interactants unique resources and opportunities for managing how they display attention toward multiple, concurrent engagements. Unlike a ringing telephone, a ring signifying a new text message does not demand the recipient to "answer" within a set number of repeated rings. As a traditionally asynchronous form of mediated communication, text messaging does not presume a coterminous relationship between interactants' text messages and therefore, unlike Goffman's (1963) notion of the "focused encounter," do not require interactants to be interacting exclusively with only one interlocutor at a time (remote or other- wise). How recipients attend to, directly access, and respond to an MTS may thus depend on their discourse identity within the immediate face-to-face context.

In the data examined here, asynchronous properties support the project of participating in interactions across multiple modalities. In line with prior work on mobile phones (e.g., Arminen \& Leinonen, 2006; DiDomenico \& Boase, 2013; Isaacs et al., 2012), our study documents how the affordances of mobile phones can supplement the range of interactional resources typically available for enacting participation in an interaction, face-to-face or otherwise. In the first two Extracts, we showed how being the recipient of an MTS may already occupy recipiency in the copresent encounter. This local

discourse identity can be managed by attempting to attend to both engagements simultaneously (Extract 1) or, though it may be restricted to the context of multiparty talk, focusing one's attention primarily on her mobile phone (Extract 2).

In contrast, our analysis of Extracts 3 and 4 consisted of MTS recipients who occupy speakership 
and thus must deal with different interactional contingencies in the local interaction. When the MTS recipient occupies speakership in the encounter, one may delay attending to the mobile phone until the completion of an in-progress activity. For instance, in Extract 3, Julie only briefly glances at her mobile phone when she occupies the discourse identity of current speaker and, later on, shifts her attention more exclusively toward the mobile phone when her discourse identity is being recipient to Faye. Thus, occupying speakership while being the recipient of an MTS notification may more strongly constrain when and how participants attend to their mobile-mediated engagement (for instance, accessing one's device to quickly read a text message vs. further manipulating it with one's hands to compose and send a response). This is in contrast to the first two extracts, where enacting recipiency in the copresent activity allows more scope in how the recipient goes about attending to her mobile phone.

Alternatively, an MTS recipient may also use the mobile's audible notification — and potentially the content of the text message itself - as a resource to manage discourse identities in the local conversation as well as to transcend the technological boundaries of each interaction (cf. DiDomenico \& Boase, 2013). In Extract 5, Cam's oral reporting of a text message, which is presumably followed by a response as he is composing it in real time, imports his text-mediated interaction and thus making his mobile-related involvement more interactionally available to the interlocutors in the copresent conversation. To be sure, Beth orients to this availability as she asks for more information regarding the identity of the person who has just messaged Cam. This is especially noteworthy when considered against the broader backdrop of accountability (Buttny, 1993; Robles, DiDomenico, \& Raclaw, 2018) and the interactional management of joint attention (Mondada, 2014) in interaction. While it is itself noteworthy that mobile phone use in the midst of copresent interaction is rarely made accountable throughout our broader collection of interactions involving mobile phones, ${ }^{7}$ we found the practice of orally reporting text message content to be a further method for participants to deal with one's mobile-related interactions while also display 
one's accountability to maintain a certain degree of involvement and engrossment within the copresent encounter.

It is also worth pointing out that the core interactional problems participants deal with throughout our data do not appear to be completely new, nor do they seem oriented to by participants as deserving of moral judgment in practice. The matter of initiating, suspending, and resuming one's activity (whether embodied or verbal) in the midst of a social encounter represents a generic interactional problem that interactants routinely deal with, regardless of its technological dimensions (see Haddington et al., 2014). Furthermore, as others have argued, the use of any new technological means for communication does not necessarily lead to fundamentally different under- standings of communication (Aakhus \& DiDomenico, 2016; Aakhus \& Jackson, 2005). Instead, we may see how the basic underlying principles of human interaction continue to operate while the specific practices for accomplishing interaction may differ. As our study shows, interactants are capable of developing ways to adapt and work around the emergent problems (and affordances) that are implicated with the use of a given communication technology. In this sense, then, the interpersonal management of mobile phone use during conversation may best be thought of as merely an extension of routine and long-standing problems of emergent human sociality.

One area ripe for further research is whether successive individual audible chimes or vibrations ought to still be considered a summons at all (i.e., as an initial bid to initiate an interaction). Mobile phones may produce notification chimes to signal the receipt of any text message, regardless of whether it is initiating a new course of action on behalf of the MTS initiating party or only indicating a new message in a previously initiated exchange between the parties. In this sense, text messaging can parallel what others (e.g., Schegloff, 2007; Schegloff \& Sacks, 1973) have called "continuing states of incipient talk" wherein turn-by-turn talk may occur and be followed by a lapse that brings a semipermeable close 
to the interaction, yet further turn-by-turn talk may be (re-)initiated at any time. This state of talk does not feature any type of terminal exchange (e.g., "Bye," "See ya," "Ciao," etc., see Schegloff \& Sacks , 1973) prior to the lapse and is typically reinstated following the lapse without requiring any type of greeting or formal restart. In face-to- face contexts, interactional circumstances such as copresence and other features specific to the type of activity or environment (e.g., a family dinner, passengers sitting adjacently on a plane) also characterize continuing states of incipient talk. In the case of text messages, participants may engage in text-message interactions over an extended period of time while not needing to exchange goodbyes (i.e., to close down the interaction) or greetings (to reinitiate the interaction). In this way, participants may use the affordances of the mobile phone to stay "continually connected" through short exchanges of text messages, followed by lapses, and then further back-andforth texting, all in the midst of ongoing or distinct face-to-face encounters. Although the current study provides insight into how mobile text message activity may shape the negotiation of discourse identities, future research that includes participants' text messages is needed to investigate this aspect of how mobile-mediated interactions become interactionally consequential and seamlessly integrated into the fabric of daily social life.

\section{Conclusion}

In sum, this article has examined the way that new uses of technology may facilitate simultaneous participation across face-to-face and technologically mediated interactions. Rather than relying on deterministic views regarding the impact of technology on our social lives, our affordances-based perspective highlighted the interplay between the affordances made available by communication technologies similar to the mobile phone and the ways these emerge as interactionally consequential within the normative organization of ordinary conversation. The mobile phone's affordances serve as a 
further interactional resource to initiate and manage mediated incipient interactions alongside or in substitute of in-progress copresent interaction. In this way, the asynchronous affordances of mobile phones make possible a type of dynamic switching between different, noncollocated interactions. Put another way, our study shows how the affordances of mobile text messaging, especially its asynchronous properties, can support interactants' abilities to manage social engagements across different modalities. The fine-grained, qualitative perspective we have offered lies in stark contrast to public perceptions of, and discourses surrounding, how mobile phones have positively or negatively affected interpersonal communication practices and outcomes. Examining technology use in action, in situ, can thus provide a glimpse into how interactants are able to navigate the multiple, potentially overlapping contingencies that come with being a part of mundane scenarios of technology use.

\section{Notes}

1. Also see Tracy and Robles' (2013) discussion of interactional identities for a slightly broader conceptualization that includes both these discourse intrinsic participant roles as well as broader social roles (e.g., doctor, mother, etc.).

2. From a methodological standpoint, we must also note the complexity of how a mobile text summons (MTS) can be "responded to" by its recipient by deploying a wide range of nonverbal resources. In terms of displaying their engagement to such audible chimes or vibrations, MTS recipients' subsequent embodied behaviors may include some or all of the following: glancing toward the mobile phone, picking it up and accessing (reading) the text message, or further manipulating the device using the fingers of one or both hands to swipe at the screen or to type a text message response. When possible, we have attempted to document as much of the rich multimodal details of how participants' engagement with their mobile phones evolves (both 
before and after an MTS occurs), yet we have also bal- anced the degree of detail to preserve the overall readability of the transcripts as much as possible.

3. See also Goodwin $(1981,1984)$ on how participants unaccountably withdraw their gaze from their interlocutors while preparing to engage in subordinate side involvements, such as eating food or smoking cigarettes.

4. An example of such a practice for displaying (and renewing) recipiency to a multiunit turn is through the production of continuers ("mmhm," "uh huh," "yeah") and other minimal recipient responses (Schegloff, 1982).

5. It is possible that Julie withholds turning her attention to the vibrating mobile phone as ameans of displaying the priority that her ongoing turn at talk holds over the incoming MTS.

6. To preserve transcript accessibility, we have chosen to omit the minor necklace-related embodiment that occurs in the first seconds of this extract from the early portion of the transcript in favor of briefly referencing it when relevant in our analysis.

7. Indeed, although broader discourses surrounding mobile phone etiquette might suggest certain types of concurrent mobile phone use during conversation to be "rude," we have only a single, teasing instance of such occurring in our collection.

\section{References}

Aakhus, M., \& DiDomenico, S. (2016). Language and interaction in new-media environments. In L. D. Saussure \& A. Rocci (Eds.), Handbook of verbal communication (pp. 375-1394). Berlin, Germany: Mouton de Gruyter.

Aakhus, M., \& Jackson, S. (2005). Technology, interaction, and design. In K. L. Fitch \& R. E. Sanders (Eds.), Handbook of language and social interaction (pp. 411-435). Mahwah, NJ: Lawrence 
Erlbaum.

Aaltonen, T., Arminen, I., \& Raudaskoski, S. (2014). Photo sharing as a joint activity between an aphasic speaker and others. In Interacting with objects: Language, materiality, and social activity (pp. 125-144). doi:10.1075/z.186.06aal

Arminen, I., \& Leinonen, M. (2006). Mobile phone call openings: Tailoring answers to person- alized summonses. Discourse Studies, 8, 339-368. doi:10.1177/1461445606061791

Beck, J. (2016, June 14). Ignoring people for phones is the new normal: A study looks at how phone snubbing_ "phubbing"-becomes socially acceptable. The Atlantic. Retrieved from https://www.theatlantic.com/technology/archive/2016/06/ignoring-people-for-phones-is- thenew-normal-phubbing-study/486845/

boyd, D. (2014). It's complicated: The social lives of networked teens. New Haven, CT: Yale University Press.

Burgoon, J. K., Buller, D. B., Hale, J. L., \& de Turck, M. A. (1984). Relational messages associated with nonverbal behaviors. Human Communication Research, 10, 351-378.

Buttny, R. (1993). Social accountability in communication. London: Sage.

Caughlin, J. P., \& Sharabi, L. L. (2013). A communicative interdependence perspective of close relationships: The connections between mediated and unmediated interactions matter. Journal of Communication, 63, 873-893. doi:10.1111/jcom.12046

Clayman, S. E. (2013). Turn-constructional units and the transition-relevance place. In J. Sidnell \& T. Stivers (Eds.), Handbook of conversation analysis (pp. 150-166). Oxford, UK: WileyBlackwell.

Curran, J., Fenton, N., \& Freedman, D. (2016). Misunderstanding the Internet. Routledge. doi:10.4324/9780203146484 
DiDomenico, S. M., \& Boase, J. (2013). Bringing mobiles into the conversation: Applying a conversation analytic approach to the study of mobiles in co-present interaction. In D. Tannen \& A. Trester (Eds.), Discourse 2.0: Language and new media (pp. 119-131). Washington, DC: Georgetown University Press.

Ekman, P., \& Friesen, W. V. (1969). The repertoire of nonverbal behavior: Categories, origins, usage, and coding. Semiotica, 1(1), 49-98. doi:10.1515/9783110880021.57

Fisher, C. (2015, September 30). Turkle, times, technology, trauma-Yet again [Web log post]. Retrieved from https://madeinamericathebook.wordpress.com/2015/09/30/turkle-timestechnology-trauma-yet-again/

Ford, C. E. (2008). Women speaking up: Getting and using turns in workplace meetings. New York, NY: Palgrave Macmillan.

Gershon, I. (2017). Language and the newness of media. Annual Review of Anthropology, 46, 15-31. doi:10.1146/annurev-anthro-102116-041300

Gibson, J. (1977). The theory of affordances. In R. E. Shaw \& J. Bransford (Eds.), Perceiving, acting, and knowing: Toward an ecological psychology (pp. 67-82). Hillsdale, NJ: Lawrence Erlbaum.

Goffman, E. (1963). Behavior in public places: Notes on the social organization of gatherings. New York, NY: The Free Press.

Goodwin, C. (1980). Restarts, pauses, and the achievement of a state of mutual gaze at turn- beginning. Sociological Inquiry, 50, 272-302.

Goodwin, C. (1981). Conversational organization: Interaction between speakers and hearers. New York, NY: Academic Press.

Goodwin, C. (1984). Notes on story structure and the organization of participation. In J. M. Atkinson \& J. Heritage (Eds.), Structures of social action (pp. 225-246). Cambridge, UK: Cambridge 
University Press.

Goodwin, C. (2000). Action and embodiment within situated human interaction. Journal of Pragmatics, 32, 1489-1522. doi:10.1016/s0378-2166(99)00096-х

Haddington, P. (2006). The organization of gaze and assessments as resources for stance taking. Text \& Talk, 26, 281-328. doi:10.1515/TEXT.2006.012

Haddington, P., Keisanen, T., Mondada, L., \& Nevile, M. (2014). Towards multiactivity as a social and interactional phenomenon. In P. Haddington, T. Keisanen, L. Mondada \& M. Nevile (Eds.), Multiactivity in social interaction: Beyond multitasking (pp. 3-32). Amsterdam, The Netherlands: John Benjamins. doi:10.1075/z.187.01had

Haddington, P., \& Rauniomaa, M. (2011). Technologies, multitasking, and driving: Attending to and preparing for a mobile phone conversation in a car. Human Communication Research, 37, 223254. doi:10.111/j.1468-2958.2010.01400.x

Hampton, K. N. (2016). Persistent and pervasive community: New communication tech- nologies and the future of community. American Behavioral Scientist, 60, 101-124. doi: $10.1177 / 0002764215601714$

Hampton, K. N., Goulet, L. S., \& Albanesius, G. (2015). Change in the social life of urban pub- lic spaces: The rise of mobile phones and women, and the decline of aloneness over thirty years. Urban Studies, 52, 1489-1504. doi:10.14361/9783839408650-009

Hepburn, A., \& Bolden, G. (2013). The conversation analytic approach to transcription. In J. Sidnell \& T. Stivers (Eds.), The handbook of conversation analysis (pp. 57-76). Chichester, UK: WileyBlackwell. doi:10.1002/9781118325001.ch4

Heritage, J., \& Sefi, S. (1992). Dilemmas of advice: Aspects of the delivery and reception of advice in interactions between health visitors and first time mothers. In P. Drew \& J. Heritage (Eds.), Talk 

at work (pp. 359-417). Cambridge, UK: Cambridge University Press.

Hoey, E. M. (2015). Lapses: How people arrive at, and deal with, discontinuities in talk. Research on Language and Social Interaction, 48(4), 430-453. doi:10.1080/08351813.2015.1090116

Holt, E. (1996). Reporting on talk: The use of direct reported speech in conversation. Research on Language \& Social Interaction, 29, 219-245.

Humphreys, L. (2005). Cell phones in public: Social interaction in a wireless era. New Media and Society, 7, 813-836. doi:10.11777/1461444805058164

Hutchby, I. (2001). Conversation and technology: From the telephone to the Internet. Cambridge, UK: Polity Press. doi:10.1108/itp.2002.15.4.362.1

Isaacs, E., Szymanski, P., Yamauchi, Y., Glasnapp, J., \& Iwamoto, K. (2012). Integrating local and remote worlds through channel blending. In Proceedings of the ACM 2012 Conference on Computer Supported Cooperative Work (pp. 617-626). Seattle: ACM Press. doi:10.1145/2145204.2145299 Jefferson, G. (1988). On the sequential organization of troubles-talk in ordinary conversation. Social Problems, 35, 418-441.

Jefferson, G. (2004). Glossary of transcript symbols with an introduction. Pragmatics and Beyond New Series, $125,13-34$.

Katz, J. E., \& Aakhus, M. A. (2002). Perpetual contact: Mobile communication, private talk, public performance. Cambridge, UK: Cambridge University Press. doi:10.1017/ cbo9780511489471

Kurtzberg, T. R., \& Gibbs, J. L. (2017). Distracted: Staying connected without losing focus. Santa Barbara, CA: ABC-CLIO.

Lerner, G. H. (2003). Selecting next speaker: The context sensitive operation of a context-free organization. Language in Society, 32, 177-201.

Licoppe, C. (2004). “Connected” presence: The emergence of a new repertoire for managing social 
relationships in a changing communication technoscape. Environment and Planning D: Society and Space, 22, 135-156. doi:10.1068/d323t

Licoppe, C. (2010). The "crisis of the summons": A transformation in the pragmatics of "notifi- cations," from phone rings to instant messaging. The Information Society, 26, 288-302. Doi $: 10.1080 / 01972243.2010 .489859$

Ling, R. (2012). Taken for grantedness: The embedding of mobile communication into society. Cambridge, MA: MIT Press. doi:10.1080/07370024.2017.1326008

Ling, R., \& Campbell, S. W. (2009). The reconstruction of space and time: Mobile communica- tion practices. New Brunswick, NJ: Transaction. doi:10.1177/0094306110361589dd

Mandelbaum, J. (2013). Storytelling in conversation. In J. Sidnell \& T. Stivers (Eds.), The handbook of conversation analysis (pp. 492-510). Malden, MA: Wiley-Blackwell. doi:10.1002/9781118325001.ch24

Miller-Ott, A., \& Kelly, L. (2015). The presence of cell phones in romantic partner face-to-face interactions: An expectancy violation theory approach. Southern Communication Journal, 80, 253270. doi:10.1080/1041794x.2015.1055371

Mondada, L. (2014). Conventions for multimodal transcription. Retrieved from https://mainly. sciencesconf.org/conference/mainly/pages/Mondada2013_conv_multimodality_copie.pdf

Nagy, P., \& Neff, G. (2015). Imagined affordance: Reconstructing a keyword for communica- tion theory. Social Media + Society, 1(2), 299-313. doi:10.1177/2056305115603385

Norman, D. A. (1999). Affordance, conventions, and design. Interactions, 6, 38-43. doi: $10.1145 / 301153.301168$

Oppenheimer, M. (2014, January 17). Technology is not driving us apart after all. The New York Times. Retrieved from https://www.nytimes.com/2014/01/19/magazine/technology-is-not- driving-us- 
apart-after-all.html

Pettegrew, L. S., \& Day, C. (2015). Smart phones and mediated relationships: The changing face of relational communication. Review of Communication, 15, 122-139. doi:10.1080/15 358593.2015.1044018

Pomerantz, A. (1980). Telling my side: "Limited access" as a "fishing" device. Sociological Inquiry, 50(3-4), 186-198. doi:10.1111/j.1475-682x/1980.tb00020.x

Pomerantz, A. (1984) 'Agreeing and Disagreeing with Assessments: Some Features of Preferred/Dispreferred Turn Shapes'. In J. M. Atkinson \& J. Heritage (Eds.) Structures of Social Action: Studies in Conversation Analysis. Cambridge: Cambridge University Press.

Pomerantz, A., \& Fehr, B. J. (1997). Conversation analysis: An approach to the study of social action as sense making practices. Discourse as Social Interaction, 2, 64-91.

Raclaw, J., Robles, J. S., \& DiDomenico, S. M. (2016). Providing epistemic support for assess- ments through mobile-supported sharing activities. Research on language and social inter-action, 49, $362-379$.

Ralph, B., Thompson, D., Cheyne, J., \& Smilek, D. (2014). Media multitasking and failures of attention in everyday life. Psychological Research, 78, 661-669. doi:10.1007/s00426-013- 0523-7

Raymond, G., \& Lerner, G. H. (2014). A body and its involvements: Adjusting action for dual involvements. In P. Haddington, T. Keisanen, L. Mondada \& M. Nevile (Eds.), Beyond multitasking: Multiactivity in social interaction (pp. 228-245). Amsterdam, The Netherlands: John Benjamins. doi:10.1075/z.187.08ray

Reinsch, N. L., Turner, J. W., \& Tinsley, C. H. (2008). Multicommunicating: A practice whose time has come? Academy of Management Review, 33, 391-403. doi:10.5465/ amr.2008.31193450

Rice, R. E., \& Katz, J. E. (2003). Mobile discourtesy: National survey results on episodes of convergent 
public and private spheres. In K. Nyiri (Ed.), Mobile democracy: Essays on society, self and politics (pp. 53-64). Vienna, Austria: Passagen Verlag.

Robles, J. S., DiDomenico, S., \& Raclaw, J. (2018). Doing being an ordinary technology and social media user. Language \& Communication, 60, 150-167.

Rossano, F. (2012). Gaze in conversation. In J. Sidnell \& T. Stivers (Eds.), The handbook of conversation analysis (pp. 308-329). Malden, MA: Wiley-Blackwell.

Ryave, A. L. (1978). On the achievement of a series of stories. In J. Schenkein (Ed.), Studies in the organization of conversational interaction (pp. 113-132). New York, NY: Academic.

Sacks, H. (1992a). Lectures on conversation, Volume I. Cambridge, UK: Blackwell. Sacks, H. (1992b). Lectures on conversation, Volume II. Cambridge, UK: Blackwell.

Sacks, H., Schegloff, E. A., \& Jefferson, G. (1974). A simplest systematics for the organization of turntaking for conversation. Language, 50, 696-735.

Schegloff, E. A., \& Sacks, H. (1973). Opening up closings. Semiotica, 4, 289-327. doi:10.1515/ semi.1973.8.4.289

Schegloff, E. A. (1968). Sequencing in conversational openings. American Anthropologist, 70, 10751095. doi:10.1525/aa.1968.70.6.02a00030

Schegloff, E. A. (1982). Discourse as an interactional achievement: Some uses of 'uh huh' and other things that come between sentences. In D. Tannen (Ed.), Analyzing discourse: Georgetown University Roundtable on Languages and Linguistics 1981 (pp. 71-93). Washington, DC: Georgetown University Press.

Schegloff, E. A. (2007). Sequence organization in interaction: A primer in conversation analy- sis (Vol. 1). Cambridge University Press. doi: $10.1017 /$ cbo9780511791208

Sidnell, J. (2013). Basic conversation analytic methods. In J. Sidnell 
\& T. Stivers (Eds.), Handbook of conversation analysis (pp. 77-10). Blackwell. doi:10.1002/9781118325001.ch5

Stephens, K. K., Cho, J., \& Ballard, D. I. (2012). Simultaneity, sequentiality, and speed: Organizational messages about multiple-task completion. Human Communication Research, 38, 23-47. doi:10.1111/j.1468-2958.2011.01420.x

Stivers, T., \& Rossano, F. (2010). Mobilizing response. Research on Language and Social Interaction, $43,3-31$.

Streeck, J. (1993). Gesture as communication I: Its coordination with gaze and speech. Communications Monographs, 60, 275-299. doi:10.1080/03637759309376314

Tracy, K., \& Robles, S. (2013). Everyday talk: Building and reflecting identities. New York: Guilford Press.

Treem, J. W., \& Leonardi, P. M. (2013). Social media use in organizations: Exploring the affor- dances of visibility, editability, persistence, and association. Annals of the International Communication Association, 36, 143-189. doi:10.2139/ssrn.2129853

Turkle, S. (2012). Alone together: Why we expect more from technology and less from each other. New York: Basic Books.

Turkle, S. (2015). Reclaiming conversation: The power of talk in a digital age. New York: Penguin.

Wang, Z., Irwin, M., Cooper, C., \& Srivastava, J. (2015). Multidimensions of media multi- tasking and adaptive media selection. Human Communication Research, 41, 102-127. doi:10.1111/hcre.12042

Weilenmann, A., \& Larsson, C. (2002). Local use and sharing of mobile phones. In B. Brown, N. Green \& R. Harper (Eds.), Wireless world: Social and interactional aspects of the mobile age (pp. $92-$ 107). London, England: Springer Verlag. 
Zimmerman, D. H. (1998). Identity, context and interaction. In C. Antaki \& S. Widdicombe (Eds.), Identities in talk (pp. 87-106). London, England: Sage. 